\title{
Assessment of fitness for surgical procedures and the variability of anaesthetists' judgments
}

\author{
M E WILSON, N B WILlIAMS, P J F BASKETT, J A BENNETT, A M SKENE
}

\section{Summary and conclusions}

Ten anaesthetists were asked to make judgments on fitness for elective operation on data derived from 200 patients. The extent of their agreement was measured using a kappa statistic, and clusters of anaesthetists who agreed well with each other were identified. Using an alternative technique, the "true" fitness category of each patient was estimated using a maximum likelihood method which estimated the error involved in making judgments on limited amounts of information. It was possible to compare the performance of each anaesthetist against the consensus and to measure deviation on an "optimism-pessimism" continuum. A simple questionnaire predicted fitness for operation by all 10 anaesthetists in $96 \%$ of cases.

\section{Introduction}

The difficulty of comparing performance among anaesthetists in assessing the fitness of patients for operation is well known. One solution is to measure agreement between them using a kappa statistic ${ }^{1}$ which does not require knowledge of the true category of each patient. This forms the first part of the present paper. An alternative is to derive mathematically a group opinion for each patient and this is shown in the second part. It provides a consensus about fitness against which judgments

Bristol Royal Infirmary, Bristol

M E WILSON, PHD, FFARCS, consultant senior lecturer in anaesthetics, University of Bristol (present address: Royal United Hospital, Bath BA1 3NG

N B WILLIAMS, MB, FFARCS, consultant in anaesthetics

Frenchay Hospital, Bristol

P J F BASKETT, MB, FFARCs, consultant in anaesthetics

J A BENNETT, MRCS, FFARCS, consultant in anaesthetics

University College, London

A M SKENE, PHD, lecturer, department of statistics and computer science (present address: Department of Mathematics, University of Nottingham) can be compared and allows the magnitude and type of errors made by individual anaesthetists in assessing a patient to be estimated. In addition it can be used to measure the relative contribution made by the various elements of the preoperative assessment. Finally, it is possible to look back through the records and pick out examples of each category to see how various items of information have influenced the classification.

\section{Patients and methods}

The four clinical authors visited 200 patients in three Bristol hospitals to gather and record the relevant clinical information. The elective surgery undertaken was representative of that to be expected in a typical week and covered general surgical, gynaecological, orthopaedic, ear, nose, and throat, thoracic, plastic, and neurosurgical procedures.

The clinical information was recorded on a special form which included details of the patient's age, sex, and proposed operation. It was divided into three sections. Level A dealt with the patient's general health, functional ability, and relevant medical and anaesthetic history-that is, those categories which might influence the choice or conduct of an anaesthetic. It was obtained by direct questioning without reference to case notes (fig 1). Relevant information that could be obtained by simple "end of the bed" observation of the patientfor example, cyanosis, finger clubbing, dyspnoea at rest, head and neck abnormalities-was included. Most information was recorded as "yes" or "no" answers to specific questions, but space was provided to amplify any answer that might be considered of anaesthetic importance.

Level B contained information from the patient's case notes, including relevant details of the history, physical examination, and correspondence. Level $\mathrm{C}$ consisted of relevant special investigations.

Ten representative consultant anaesthetists, including the four clinical authors, participated in the assessment. The design was so arranged that each patient was assessed by five anaesthetists so that comparison between pairs was possible. In all, 3000 judgments were produced for analysis. When making an assessment the only information available was that contained in the completed forms, which were considered in strict order. Initially a decision was made in the light of section A, then section B was uncovered and a further assessment made, and finally all of the information was considered.

With each level of information, the patient's fitness for operation was judged on an arbitrary scale of 1-6. This took into account both the physical status and the proposed surgery. A perfectly fit patient in whom no problems were expected was classified as category 1 , whereas 


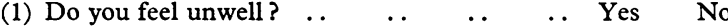

(2) Have you had any serious illnesses in

(3) Do you get more short of breath on exertion than other people of your own age ? . . . . Y Yes No

(4) Do you have any cough?

(5) Do you have any wheeze? $\quad . . \quad \ldots . \quad \ldots$ Yes No

(6) Do you have any chest pain on exertion?

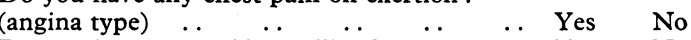

(7) Do you have any ankle swelling? .. . . Yes No

(8) Have you taken any medicine or pills in the last 3 months ? (including excess alcohol) .. Yes No

(9) Have you any allergies? $\quad . \quad \ldots . \quad \ldots$ Yes No

(10) Have you had an anaesthetic in the last 2 months? $\quad . \quad$. . . . . . . . Yes

(11) Have you or your relatives had any problems with a previous anaesthetic? .. $\quad . . \quad \ldots$ Yes

12) Observation of serious abnormality from "end of bed" (which might affect anaesthetic) . . Yes

(13) Date of last menstrual period

Other comments:

FIG 1-Questionnaire designed to elicit level $\mathrm{A}$ information.

a category 6 patient was expected to die during the operation or shortly afterwards. In analysing the data the scale was reduced to four categories by combining 4,5 , and 6 because only a few patients were assigned to each.

\section{Results}

PART I

The method for measuring agreement can best be explained using a simple example. Suppose two anaesthetists, A and B, examine the same 100 patients and independently decide whether each patient is fit or unfit for anaesthesia. A considers 90 patients to be fit and B 85 . Both agree that 80 patients are fit and five patients are unfit. They disagree over the remaining 15 patients. The total agreement is $80+5=85$, or 0.85 as a fraction of the total number of patients. But a certain amount of agreement is to be expected by chance alone. As both observers assessed a high proportion of patients as fit then the chance of agreeing that any one patient is fit is also high.

The expected frequency of chance agreement "fit" is $\frac{85 \times 90}{100}=76.5$ and the expected frequency of chance agreement "unfit" is $\frac{10 \times 15}{100}=1 \cdot 5$. So by chance alone they ought to agree upon $76 \cdot 5+1 \cdot 5=$

78 patients. The observed agreement of 85 patients now looks less impressive, and it is necessary to make some correction for chance agreements by using the kappa statistic:

$$
\kappa=\frac{P_{0}-P_{e}}{1-P_{e}}
$$

where $P_{0}$ is the sum of the observed proportion of agreements and $P_{e}$ is the sum of the expected proportion of agreements. In the above example $\kappa \times \frac{0.85-0.78}{1-0.78}=0.32$.

A kappa statistic may be calculated for more than two observers, and a weighted kappa may be calculated if the observations are measured on an ordinal scale. ${ }^{2}$ The variance of kappa may also be obtained so that tests of significance can be performed. ${ }^{3}$

At each of the four fitness categories anaesthetists agreed better than by chance $(p \leqslant 0.001)$. For all categories together the overall measure of agreement was $\kappa=0.366$ using level $A$ information, $\kappa=0.360$ using level $\mathrm{A}$ and $\mathrm{B}$ information, and $\kappa=0.382$ using all the available information. The best agreement arose over the decision that a patient belonged to category $1(\kappa=0.592$ using $A$ information and $\kappa=0.626$ using $A, B$, and $C$ information). There was poorest agreement over classification of the least fit patients when all the available information was used.

A weighted kappa statistic, measuring the agreement between pairs, of greater than 0.6 was chosen arbitrarily to illustrate pairs of anaesthetists who agreed well (fig 2). It is obvious that anaesthetist 8 agreed well with many of his colleagues. Others agreed poorly: anaesthetist 6 , for example, had $\kappa$ values of $0 \cdot 18,0 \cdot 26,0 \cdot 14$, and $0 \cdot 22$ when paired with anaesthetists $1,3,5$, and 10 respectively.

PART II

Since a "true" measure of a patient's category cannot be obtained, a consensus score at each level of information was calculated using a procedure described by Dawid and Skene. ${ }^{4}$ This procedure takes into account the fact that certain observers are more consistent than others (fig 2) and accordingly their assessments are given a higher weight. In effect, the consensus score for an individual patient depends not only on the assessors' opinions but also on each assessor's accuracy with other patients in the trial. It also yields alternative measures of the performance of each anaesthetist, which we call the observer error rates.

The largest number of patients $(82(41 \%)$ using level $\mathrm{A}$ and 86 $(43 \%)$ using all available information) were placed in category 1 . There were only a few category 4 patients $(16(8 \%)$ using level $\mathrm{A}$ and 23 $(11.5 \%)$ using $\mathrm{A}, \mathrm{B}$, and $\mathrm{C}$ information; table $\mathrm{I})$. The increased amount of information had little effect on the total number of patients placed in category 1 .

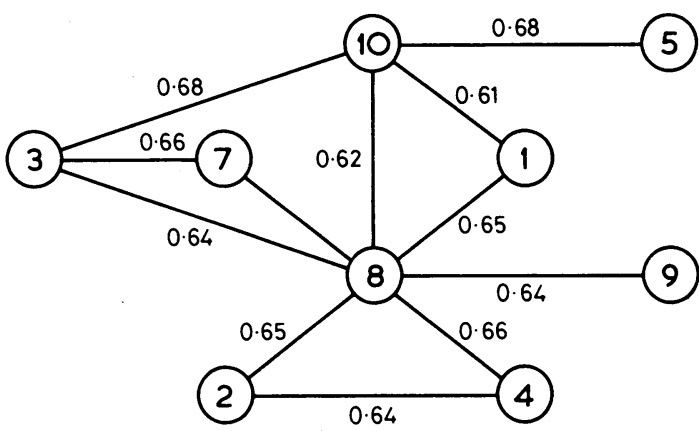

FIG 2-Pairs of anaesthetists agreeing about fitness categories with $\kappa>0.6$ when using $A, B$, and $C$ information.

TABLE I-Incidence rates: numbers of patients assigned by consensus opinion to each fitness category

\begin{tabular}{lccccc}
\hline & \multicolumn{4}{c}{ Fitness categories } & \\
\cline { 2 - 5 } & 1 & 2 & 3 & 4 & Total \\
\hline Questionnaire (level A) & 82 & 67 & 35 & 16 & 200 \\
All information (A, B, and C) & 86 & 54 & 37 & 23 & 200 \\
\hline
\end{tabular}

The effectiveness of A and B level information was measured by seeing how often it resulted in an assessment which agreed with that based on the full information. On level $\mathrm{A}$ information a patient thought to be in category 1 had a probability of 0.87 by consensus of being in this category, and a probability of 0.13 of being in category 2 , when full information became available (table II). This implied that if the consensus, using level $\mathrm{A}$ information, predicted that a patient belonged to category 1 the prediction was never more than one category in error. Twenty-nine per cent of patients considered least fit on level A were upgraded when more information became available.

The judgments of any one anaesthetist can be compared with the consensus to see how closely the individual agrees with the majority. For example, anaesthetist 8 correctly classified $91 \%$ of category 1

TABLE II-Probability of correct prediction of fitness category when only level $A$ or level $A$ and $B$ information was used

\begin{tabular}{|c|c|c|c|c|c|c|c|c|}
\hline \multirow{3}{*}{$\begin{array}{l}\text { Consensus of fitness } \\
\text { using all information } \\
\text { (A, B, and C) }\end{array}$} & \multicolumn{8}{|c|}{ Consensus of fitness using: } \\
\hline & \multicolumn{4}{|c|}{ A information } & \multicolumn{4}{|c|}{$A$ and $B$ information } \\
\hline & 1 & 2 & 3 & 4 & 1 & 2 & 3 & 4 \\
\hline $\begin{array}{l}1 \\
2 \\
3 \\
4\end{array}$ & $\begin{array}{l}0.87 \\
0.13 \\
0.00 \\
0.00\end{array}$ & $\begin{array}{l}0.20 \\
0.56 \\
0.23 \\
0.01\end{array}$ & $\begin{array}{l}0.03 \\
0.16 \\
0.47 \\
0.34\end{array}$ & $\begin{array}{l}0.00 \\
0.00 \\
0.29 \\
0.71\end{array}$ & $\begin{array}{l}0.93 \\
0.07 \\
0.00 \\
0.00\end{array}$ & $\begin{array}{l}0.07 \\
0.78 \\
0.15 \\
0.00\end{array}$ & $\begin{array}{l}0.02 \\
0.12 \\
0.60 \\
0.26\end{array}$ & $\begin{array}{l}0.00 \\
0.02 \\
0.25 \\
0.73\end{array}$ \\
\hline
\end{tabular}


patients compared with the consensus, $87 \%$ of category 2 patients, and so on (table III). Close inspection of the estimated error rates revealed the categories of patients where an individual anaesthetist differed or agreed most closely with the consensus. For example, anaesthetist 8 was good at identifying category 1 patients, but erred on the safe side with category 4 patients.

TABLE III-For each consensus fitness category the estimated probability of a patient being placed in each fitness category by anaesthetist 8 using all the information $(A, B$, and $C)$

\begin{tabular}{ccccc}
\hline $\begin{array}{c}\text { Consensus } \\
\text { fitness } \\
\text { categories }\end{array}$ & \multicolumn{4}{c}{$\begin{array}{c}\text { Anaesthetist 8's } \\
\text { fitness categories }\end{array}$} \\
\hline & 1 & 2 & 3 & 4 \\
1 & $\mathbf{0 . 9 1}$ & 0.09 & 0.00 & 0.00 \\
2 & 0.08 & $\mathbf{0 . 8 7}$ & 0.05 & 0.00 \\
3 & 0.00 & 0.00 & $\mathbf{1 . 0 0}$ & 0.00 \\
4 & 0.00 & 0.00 & 0.36 & $\mathbf{0 . 6 4}$ \\
\hline
\end{tabular}

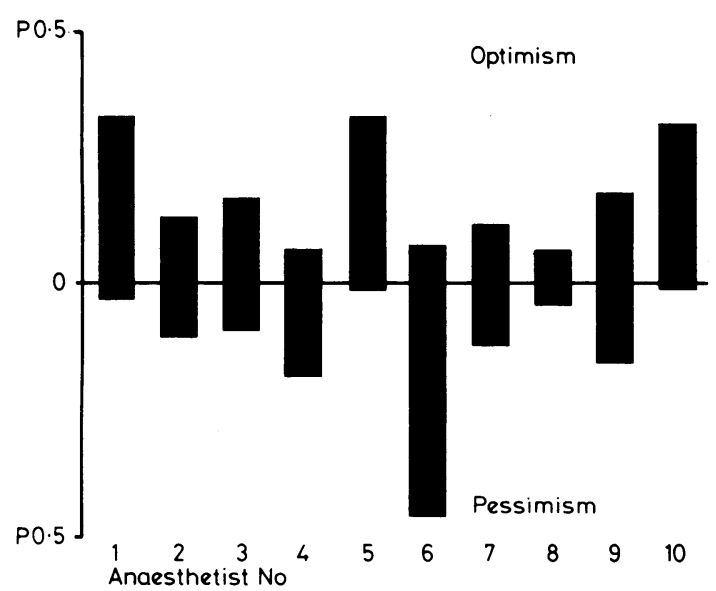

FIG 3-Degree of optimism and pessimism shown by each anaesthetist when assessing $\mathrm{A}, \mathrm{B}$, and $\mathrm{C}$ information. The shorter the bar the closer the assessment to the consensus opinion.

TABLE IV-Percentage of patients classified as category 1 on level A information correctly classified as category 1 or 2 when all information $(A, B$, and $C)$ was used

\begin{tabular}{ccc}
\hline & \multicolumn{2}{c}{$\begin{array}{c}\text { Consensus fitness category } \\
\text { based on full information }(\mathrm{A}, \mathrm{B}, \text { and } C)\end{array}$} \\
\cline { 2 - 3 } Anaesthetist No & Category 1 & Category 1 or 2 \\
\hline 1 & 76 & 96 \\
2 & 83 & 97 \\
3 & 85 & 97 \\
4 & 91 & 100 \\
5 & 84 & 97 \\
6 & 87 & 100 \\
7 & 85 & 100 \\
8 & 83 & 100 \\
9 & 76 & 96 \\
10 & 75 & 97 \\
\hline
\end{tabular}

Perfect agreement between an individual and the consensus would obviously be represented by a diagonal of 1.00. Figures greater than zero to the right of the diagonal imply that the anaesthetist judges some patients less fit than the consensus - that is, he is a "pessimist" -while figures above zero to the left imply that he is an "optimist." An individual's degree of optimism and pessimism can be calculated using error and incidence rates, and he can then discover the magnitude and direction of his deviation from the consensus (fig 3 ).

Seven anaesthetists predicted correctly that a given patient belonged in category 1 in at least $80 \%$ of cases (table IV). Since it probably did not matter if a patient thought to belong to category 1 was really in category 2 , when these two were combined 10 anaesthetists were correct on at least $96 \%$ of occasions.

Since category 1 could be successfully identified using A level information only, we examined each item to see how well it fulfilled its function (table V). If a patient judged not to belong to category 1
TABLE v-Number of "yes" replies to each item of level $A$ information and likelihood ratio of each item

\begin{tabular}{|c|c|c|c|c|c|}
\hline \multirow{2}{*}{$\begin{array}{l}\text { Question } \\
\text { No }\end{array}$} & \multicolumn{2}{|c|}{$\begin{array}{l}\text { No of "yes" replies } \\
\text { in patients belonging to }\end{array}$} & \multirow{2}{*}{$\begin{array}{c}\text { True- } \\
\text { positive } \\
\text { proportion }\end{array}$} & \multirow{2}{*}{$\begin{array}{c}\text { False- } \\
\text { positive } \\
\text { proportion }\end{array}$} & \multirow{2}{*}{$\begin{array}{l}\text { Likelihood } \\
\text { ratio }\end{array}$} \\
\hline & $\begin{array}{c}\text { Category } \\
1\end{array}$ & $\begin{array}{c}\text { Categories } \\
2,3,4\end{array}$ & & & \\
\hline $\begin{array}{r}1 \\
2 \\
3 \\
4 \\
5 \\
6 \\
7 \\
8 \\
9 \\
10 \\
11 \\
12\end{array}$ & $\begin{array}{r}6 \\
16 \\
6 \\
2 \\
1 \\
1 \\
2 \\
31 \\
10 \\
3 \\
5 \\
7\end{array}$ & $\begin{array}{r}13 \\
61 \\
43 \\
30 \\
23 \\
9 \\
21 \\
86 \\
32 \\
25 \\
7 \\
46\end{array}$ & $\begin{array}{l}0.080 \\
0.213 \\
0.080 \\
0.027 \\
0.013 \\
0.013 \\
0.027 \\
0.413 \\
0.133 \\
0.040 \\
0.067 \\
0.093\end{array}$ & $\begin{array}{l}0.104 \\
0.488 \\
0.344 \\
0.240 \\
0.184 \\
0.072 \\
0.168 \\
0.688 \\
0.256 \\
0.200 \\
0.056 \\
0.368\end{array}$ & $\begin{array}{r}1 \cdot 3 \\
2 \cdot 3 \\
4 \cdot 3 \\
8.9 \\
14 \cdot 1 \\
5.5 \\
6 \cdot 2 \\
1 \cdot 7 \\
1.9 \\
5 \cdot 0 \\
0.8 \\
4.0\end{array}$ \\
\hline $\begin{array}{l}\text { Total No } \\
\text { of patients }\end{array}$ & 75 & 125 & & & \\
\hline
\end{tabular}

by the consensus answered "yes" to an item this was classed as a truepositive response, and if he belonged to category 1 and answered "yes" this was classed as a false-positive response. The ratio of the true-positive to false-positive proportions provided a measure of the usefulness of the item (the likelihood ratio $(\mathrm{LR})^{5}$ ). An LR of 1 meant that the item provided no information and the larger the value of the LR the more useful the item. A wheeze or a cough (question 4 and 5) was a powerful indicator of disease, whereas asking a patient if he felt well (question 1) was of little help. Many patients who were eventually classified as category 1 felt unwell, took medicines, had allergies, or had a personal or family history of previous anaesthetic problems. Once consensus categories had been established it was possible to go through the records and see what information was responsible for a change of opinion. Undetected hypertension (three patients) and anaemia (three patients) were reasons for downgrading patients from category 1 to category 2. Conversely, a normal physical examination allowed four patients to be upgraded to category 1 , as did the absence of anaemia in another patient.

\section{Discussion}

The physical state of the patient and the proposed operation are two of many factors likely to influence postoperative mortality and morbidity. An index which could relate specific items of physical status and surgical procedure to the probable outcomes would be ideal. Goldman et $a l^{6}$ devised such an index but it was limited to a few physical signs and predicted only cardiovascular complications. There is a need for a crude "global index" for clinical decision making and for statistical purposes. But analysis presents problems because there is no way of determining the true fitness or category of anaesthetic risk of an individual patient, and an anaesthetist's judgment cannot be compared with some absolute standard. In addition the ordinal nature of the data means that some errors in judgment are potentially more serious than others.

Although the ASA scale is the most commonly used global index of physical status ${ }^{78}$ it does not take into account the severity of the proposed operation. Also it depends heavily on "incapacity" and so can exclude items which are no longer incapacitating, such as a previous myocardial infarction, or which have never been incapacitating (a neck deformity which might make intubation hazardous ${ }^{8}$ ). Therefore, we examined a scale which took the proposed operation into account in considering the risk. Our results show that anaesthetists can agree over the use of such a scale despite the lack of intermediate points, especially at the defined ends of the scale, although an exception was the very poor agreement over category 4 patients when the maximum amount of information was available.

The analysis also allowed an anaesthetist to compare with his peers along an optimism-pessimism continuum, so that his attitudes towards preoperative assessment could be critically appraised. Furthermore, individual error rates offered an explanation for agreement between anaesthetists. For example, 
anaesthetist 8 agreed with many of his colleagues (fig 2 ) because he deviated least from the consensus. No doubt anaesthetists 1 , 5 , and 10 agreed well with each other because they were all optimists ( $\kappa$ for anaesthetist 1-anaesthetist 5 was 0.55 ), and anaesthetist 6 agreed so poorly because of his extreme pessimism.

The use of a maximum likelihood technique to derive a consensus estimate of fitness for each patient made it possible to compare judgments based on increasing amounts of information (levels A, B, and C). An important point emerges from this. Patients who are thought to be perfectly fit on the basis of simple questions usually prove to be so after the traditional preoperative history and investigations. This suggests that a questionnaire might be developed for use in surgical outpatients to select patients for day surgery. But it might be of little practical use if it had to be assessed by a group of anaesthetists to determine the consensus category. If it is accepted that the difference between category 1 and 2 is of little clinical significance, then every anaesthetist was correct on $96 \%$ of occasions when level A information was used. The exact fitness of the other patients would be less important because they would still require careful examination so that the most appropriate anaesthetic technique could be chosen. The most important function of a questionnaire would therefore be to alert the anaesthetist to possible problems, when further investigation could be undertaken as an outpatient.

\section{References}

${ }^{1}$ Cohen J. A coefficient of agreement for nominal scales. Educ and Psychol Meas $1960 ; 20: 37-46$

2 Cohen J. Weighted kappa: nominal scale agreement with provision for scaled disagreement or partial credit. Psychol Bull 1968;70:213-20.

${ }^{3}$ Fleiss JL. Measuring nominal scale agreement among many raters. Psychol Bull 1971;76:378-82.

4 Dawid AP and Skene AM. Maximum likelihood estimation of observer error rates using EM algorithm. Applied Statistics 1979;28:20-8.

${ }^{5} \mathrm{McNeil}$ BJ, Keeler E, Adelstein SJ. Primer on certain elements of medical decision making. $N$ Engl f Med 1975;293:211-5.

${ }^{6}$ Goldman L, Caldera DL, Nussbaum SR, et al. Multifactorial index of cardiac risk in non-cardiac surgical procedures. N Engl f Med 1977; $297: 845-50$.

7 Owens WD, Felts JA, Spitznagel EL. ASA Physical Status Classifications. Anesthesiology 1978;49:239-43.

${ }^{8}$ Keats AS. The ASA Classification of Physical Status-a recapitulation. Anesthesiology 1978;49:233-6.

(Accepted 27 November 1979)

\title{
Prognostic importance of specific immunoreactivity in occupational bladder cancer
}

\author{
S KUMAR, G TAYLOR, P WILSON, WENDY HURST
}

\section{Summary and conclusions}

Sixty-eight workers with a history of exposure to a bladder carcinogen were followed up to see whether changes in lymphocyte immunoreactivity to a bladdercancer-cell target were predictive of the development of neoplasia of the urothelium. A twofold or greater increase in reactivity was strongly associated with the development of abnormal urinary cytology suggestive or indicative of malignant change. Changes in immunoreactivity to a non-bladder-cancer-cell target did not have this association.

The findings support the possibility that changes in lymphocyte immunoreactivity may be used to predict the onset of bladder cancer in people exposed to bladder carcinogens.

\section{Introduction}

In an earlier study we compared lymphocyte reactivity against a bladder-cancer target cell in a group of workers exposed to bladder carcinogens with that in normal people and patients with bladder cancer. ${ }^{1}$ Equivalent increases in reactivity were found in clinically normal carcinogen-exposed workers and

University Department of Bacteriology and Virology, Manchester S KUMAR, MVETSC, PHD, (head of paediatric oncology laboratory, Christie Hospital and Holt Radium Institute, Withington, Manchester M20 9BX) $P$ WILSON, PHD, postdoctoral fellow

WENDY HURST, BSC, postgraduate student

Appalachian Laboratory for Occupational Safety and Health, Morgantown, West Virginia 26505, USA

G TAYLOR, MD, (present address: Wasau Medical Centre, Wasau, Wisconsin 54401, USA) patients with bladder cancer when compared with the normal controls. The augmented reactivity was considered to be specific for bladder cancer, as differences in group reactivity against a non-bladder-cancer tumour cell were not found. Furthermore, increases in reactivity in the worker group were related to the degree of exposure to bladder carcinogens and also to the development of abnormal urinary cytology suggestive of early malignant change in the urothelium. We have now followed up the worker group to see whether serial changes in lymphocyte reactivity with time help to predict the development of bladder cancer in individual workers.

\section{Subjects and methods}

Chemical workers-Of the original group of 93 workers, 68 were available for continued study. All had been exposed to either $\alpha-$ naphthylamine containing 4-8\% $\beta$-naphthylamine or "pure" $\beta$ naphthylamine before 1952. Urinary cytology with Papanicolaou staining was carried out six-monthly and blood samples for lymphocytotoxicity studies taken at about yearly intervals over four years.

Target and effector cells-The bladder-cancer cell (FB) and control target cell (osteosarcoma) were the same as used in our earlier study. ${ }^{1}$ They were available stored in liquid nitrogen in aliquots of $1 \mathrm{ml}$ containing about $3 \times 10^{6}$ cells in medium 199 with $30 \%$ fetal calf serum and $10 \%$ dimethyl sulphoxide. To avoid the possibility of antigenic change we did not passage cells during the study. Effector lymphocytes were prepared from $20 \mathrm{ml}$ defibrinated venous blood by the method of Coulson and Chalmers ${ }^{2}$ with a phagocyte-removal step using carbonyl iron powder and magnetic separation. The cells were washed three times in Hanks's balanced salt solution containing $5 \%$ fetal calf serum.

Microcytotoxicity tests-We used two procedures for testing microcytotoxicity. The first was based on the method of Takasugi and Klein $^{3}$ as modified by Taylor et al. ${ }^{1}$ The second method used ${ }^{75} \mathrm{Se}-$ selenomethionine incorporation to measure residual cells, as described by Brooks et al. ${ }^{4}$ With each method five lymphocyte:target-cell ratios were set up, each in replicates of eight. The ratio of lymphocytes to 